\title{
Highlights from the Paediatric and Congenital Interventional Cardiology Early-Career Society (PICES) 2019 Activities
}

\author{
Sebastian Góreczny ${ }^{1}$, Sara Trucco ${ }^{2}$, Sarosh Percy Batlivala ${ }^{3}$, Gurumurthy Hiremath ${ }^{4}$, Wendy Whiteside ${ }^{5}$, \\ Tacy Downing, Ryan Callahan ${ }^{7}$
}

\begin{abstract}
${ }^{1}$ Department of Cardiology, Polish Mother's Memorial Hospital, Research Institute, Lodz, Poland ${ }^{2}$ Division of Paediatric Cardiology, UPMC Children's Hospital of Pittsburgh, University of Pittsburgh School of Medicine, Pittsburgh, PA, USA ${ }^{3}$ Division of Cardiology, University of Cincinnati College of Medicine, Cincinnati Children's Hospital Medical Centre, Cincinnati, Ohio, USA ${ }^{4}$ Division of Cardiology, University of Minnesota, Masonic Children's Hospital, Minneapolis, MN, USA

${ }^{5}$ Division of Paediatric Cardiology, Department of Paediatrics, University of Michigan C.S. Mott Children's Hospital, Ann Arbor, MI, USA ${ }^{6}$ Department of Cardiology, Children's National Hospital and the George Washington University School of Medicine, Washington, DC, USA ${ }^{7}$ Department of Cardiology, Boston Children's Hospital and Harvard Medical School, Boston, MA, USA
\end{abstract}

Adv Interv Cardiol 2020; 16, 1 (59): 15-18 DOI: https://doi.org/10.5114/aic.2020.93908

The Paediatric and congenital Interventional Cardiology Early-career Society (PICES) was established in late 2011 to provide resources and a forum for paediatric cardiac interventionalists early in their career $[1,2]$. The mission of PICES is to foster academic and clinical advancement of early career congenital interventional cardiologists through collaborative education, research, and networking. PICES is a special interest group of the Society for Cardiovascular Angiography and Interventions (SCAI) and has multiple previous and current PICES executive committee members on the Congenital Heart Disease (CHD) council of SCAI. Currently the society consists of more than 200 members scattered across the globe.

The PICES executive committee through September 2019 was composed of President - Ryan Callahan, MD (Boston Children's Hospital), Vice President (Research) Gurumurthy Hiremath, MD (University of Minnesota Children's Hospital), Vice President (Clinical) - Sara Trucco, MD (UPMC Children's Hospital of Pittsburgh), and Secretary - Sarosh Batlivala, MD MSCI (Cincinnati Children's Hospital Medical Centre). Wendy Whiteside, MD (C.S. Mott Children's Hospital) was elected the new Vice President (Clinical) and Tacy Downing, MD (Children's National Medical Centre) was elected the new Secretary, both are two-year positions starting in September 2019. In April 2019, Sebastian Góreczny, MD (Polish Mother's Memorial Hospital) was selected for a new position named the PICES International Delegate.
The primary means of communication between PICES members has been message exchange through a closed internet group listserv. Multiple clinical questions stimulated informative discussions and in several cases led to initiation of research collaboration. The most debated issues in the last year included selection of stents for ductus arteriosus stenting, optimal treatment of abdominal aortic coarctation and bilateral renal artery stenosis, new onset of atrioventricular block with atrial septal defect device closure, post-catheterisation loss of pulse, and administration of vasodilators and novel oral anticoagulants in Fontan patients. Similarly to previous years, several academic activities, presentation opportunities and job postings were shared on the group listserv.

A Mentorship Program championed by Matthew Crystal, MD (Morgan Stanley Children's Hospital) is now in its second class and was continued in the last year. This structured program with educational grant support pairs junior interventionalists with a well-recognised senior mentor. The program ensures the continued progress of interventional congenital cardiology by directly impacting the careers of junior interventionalists and by assisting in developing the next generation of leaders, educators, and innovators in this field. The current class includes four mentor mentee pairs:

- Michael Angtuaco, MD (Arkansas Children's Hospital) mentored by Evan Zahn, MD (Cedars-Sinai Heart Institute),

\section{Corresponding author:}

Sebastian Góreczny MD, PhD, Department of Cardiology, Polish Mother's Memorial Hospital, Research Institute, $281 / 289$ Rzgowska St, 93-338 Lodz, Poland, phone: +48 4227114 78, fax: +48 4227114 70, e-mail: sebastiangoreczny@yahoo.pl

Received: 4.03.2020, accepted: 4.03.2020. 
- Carrie Herbert, MD (All Children's Hospital) mentored by Allison Cabalka, MD (Mayo Clinic),

- Gurumurthy Hiremath, MD (University of Minnesota Children's Hospital) mentored by Lee Benson, MD (SickKids Hospital),

- Sripadh Upadhya, MD (Health City Cayman Islands) mentored by Henri Justino, MD (Texas Children's Hospital).

Since the first PICES publication by Seckeler et al. several collaborative projects have ended with successful publications [3-7]. In the beginning of 2019 Taggart et al. published results of a multi-national PICES survey on variation in anticoagulation practices in the congenital cardiac catheterisation lab [8]. Subsequently Zampi et al. published a PICES study on the relationship between time to left atrial decompression and outcomes in patients receiving veno-arterial extracorporeal membrane oxygenation support [9]. Most recently Hiremath et al. presented a multi-centred experience with balloon expandable covered stents as primary therapy for haemodynamically stable traumatic aortic injuries in children [10].

Currently there are several active PICES projects including:

- Transverse aortic arch stent study - Primary Investigator Shabana Shahanavaz, MD (St. Louis Children's Hospital),

- Branch pulmonary artery stent and right ventricle size study - Petch Suntharos, MD (Nicklaus Children's Hospital),

- Fontan liver practice variation study - Kiran Mallula, MD (Children's Hospital of New Orleans),

- Left atrial decompression in hypoplastic left heart syndrome - Konstantin Averin, MD (Stollery Children's Hospital),

- Afterload from pressure-volume loops in coarctation stent patients - Gurumurthy Hiremath, MD (University of Minnesota Children's Hospital).

\section{PICES@SCAI}

The most productive conference for PICES members was at the SCAI annual meeting in Las Vegas, Nevada. PICES held a session in the main room under the theme "Getting out of Trouble" with Frank Ing, MD (UC Davis Medical Centre) as a senior faculty speaker. In addition, three PICES members presented on different types of complications and various catheter-based techniques that were helpful to address the issue: Britton Keeshan, MD (Yale New Haven Hospital) presented a case of a ruptured balloon while delivering a Sapien valve and the manoeuvres he used to successfully remove it from the body. R. Allen Ligon Jr., MD (Children's Healthcare of Atlanta/Emory University) showed how he managed an embolised pulmonary vein stent, and Jonathan Mervis, MD (Westmead Children's Hospital, Sydney, Australia) impressed the room with how he handled a pulmonary haemorrhage following a left pulmonary artery injury.
Other events included the inaugural PICES "Office Hours", where members of the PICES Executive Committee shared the PICES mission and allowed opportunities for engagement at the SCAI Booth. PICES hosted a dinner event sponsored by Penumbra Inc., where the guest speaker Shabana Shahanavaz, MD gave an incredibly informative presentation on the Penumbra Inc. products she has used. The educational dinner was an outstanding opportunity for members to meet face-to-face, network, and build relationships for the future.

Lastly, PICES in conjunction with the Society for Cardiovascular Angiography and Interventions Women in Innovations (SCAI-WIN) Healthcare Leadership Summit organised an event for women in paediatric interventional cardiology. Open to all conference attendees, this event was intended to foster networking and mentoring opportunities among female paediatric interventionalists of all experience levels.

\section{PICES@CSI Frankfurt}

The PICES group kicked off the Congenital and Structural Interventions (CSI) meeting in Frankfurt with a well-attended dinner sponsored by Occlutech (Figure 1). In a friendly atmosphere, new and more experienced PICES members discussed challenges and opportunities in the day-to-day life of aspiring interventional cardiologists. The subsequent morning breakout session "Here is another way to do it! - Novel approaches to cardiac catheterisation." was hosted by Shabana Shahanavaz, MD and Sebastian Góreczny, MD. Despite the early hour, two great senior colleagues joined the session: Prof. Neil Wilson (Retired, previously Children's Hospital of Colorado) and former PICES member Gareth Morgan, MD (Children's Hospital of Colorado). The latter introduced the beginnings of PICES and the opportunities participation in the group has brought to many. Next Sebastian Góreczny, MD presented information on distribution of international PICES members followed by a presentation of the objective benefits of 3D guidance in the catheterisation laboratory beyond colour images. Daniel McLennan, MD (University of lowa Stead Family Children's Hospital) presented a well-illustrated case series of alternative access to extracorporeal membrane oxygenation circuits for diagnostic and interventional catheterisations. Last but not least, Radwa Bedair, MD (Bristol Heart Institute, UK) shared an inventive method of Fontan baffle leak closure through the right atrium. Throughout the session Prof. Willson was ready with thought-provoking questions and invaluable comments.

\section{PICES@PICS-AICS}

The PICES group continued the year with a breakout session entitled "Trials and Tribulations - Establishing a Career as a Paediatric Cardiologist" at the Paediatric and Adult Interventional Cardiac Symposium (PICS-AICS) 

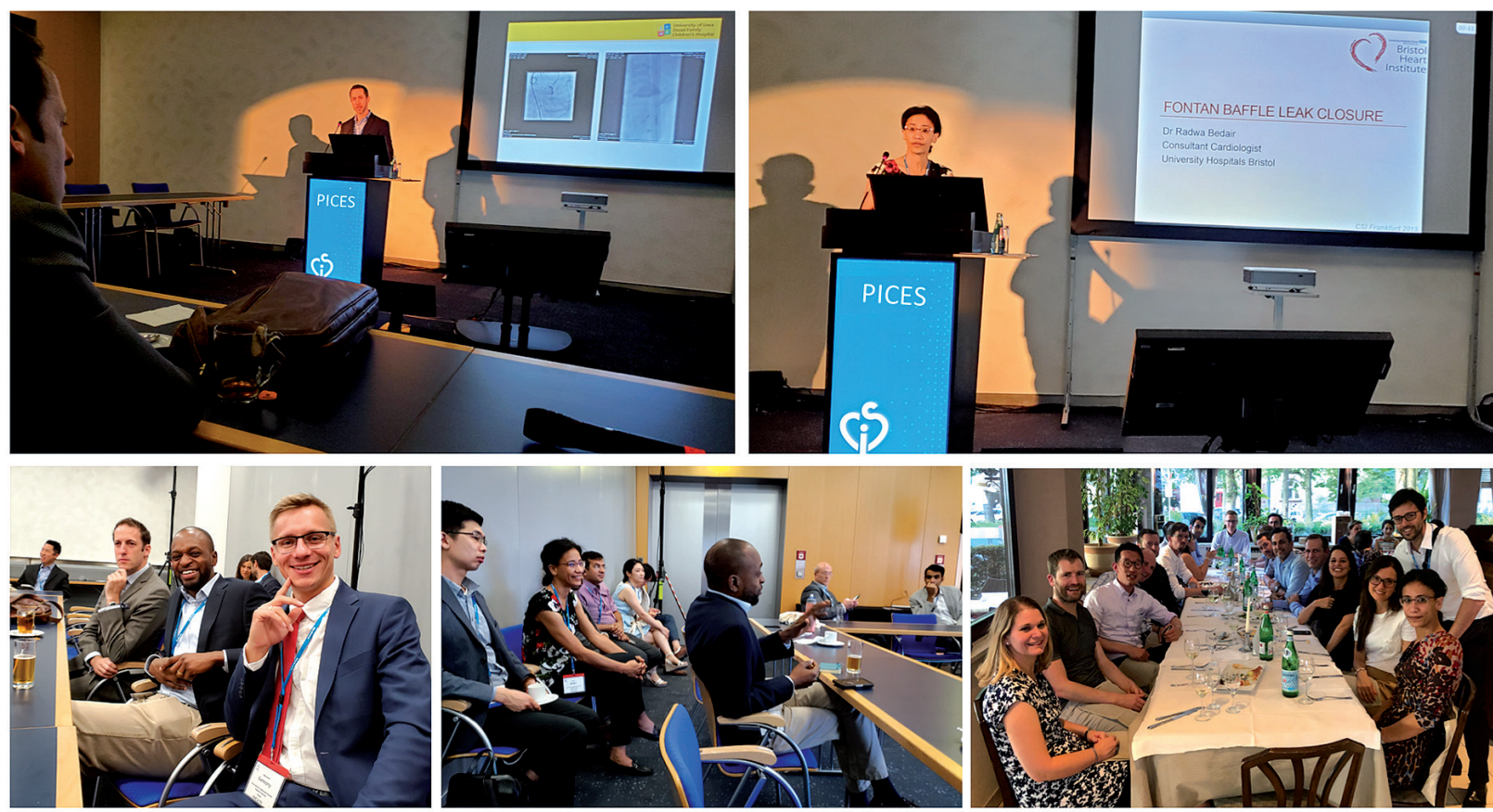

Figure 1. The Paediatric and congenital Interventional Cardiology Early-career Society (PICES) session and dinner at Congenital and Structural Interventions (CSI) meeting in Frankfurt. Images thanks to courtesy of Margot Chatenay (Occlutech) and Daniel McLennan, MD (University of Iowa Stead Family Children's Hospital)

in San Diego, CA. The highlight of the session moderated by Ryan Callahan, MD; Sara Trucco, MD, and Gurumurthy Hiremath, MD was the awarding of the second PICES Mentor Award to Lee Benson, MD (SickKids Hospital, Toronto) (Figure 2). Dr. Benson has a record of over 35 years of mentorship to fellows with over 40 directly trained paediatric interventional fellows. He has been an integral part of the PICES Mentorship Program and has always welcomed PICES members at the Toronto Course on Congenital and Structural Heart Disease. The PICES group awarded Dr. Benson for years of unwavering support, mentorship, and guidance to junior interventionalists. Two gripping case presentations followed. Jeffrey Darst, MD (Children's Hospital of Colorado) used his gifted story telling talents to present "Good Thing We Had Two Needles", setting the tone for an incredibly thought-provoking breakout session. Sanjay Sinha, MD (University of California) followed with his presentation titled "Under Pressure: A Complex Lymphatic Intervention" in which he demonstrated how a junior interventionalists can establish a niche in the field. Next, Carrie Herbert, MD (University of Texas, Southwestern) gave an emotional and inspiring speech on lessons learned through the turbulence of her early career; "What to do when the "Fasten Your Seatbelt' Light Comes On.” The session finished with a keynote speaker Audrey Marshall, MD (Harvard School of Public Health) presenting an eye-opening talk on the different ways of developing one's professional career; "Am I a tortoise or a hare? The Importance of Pace.".

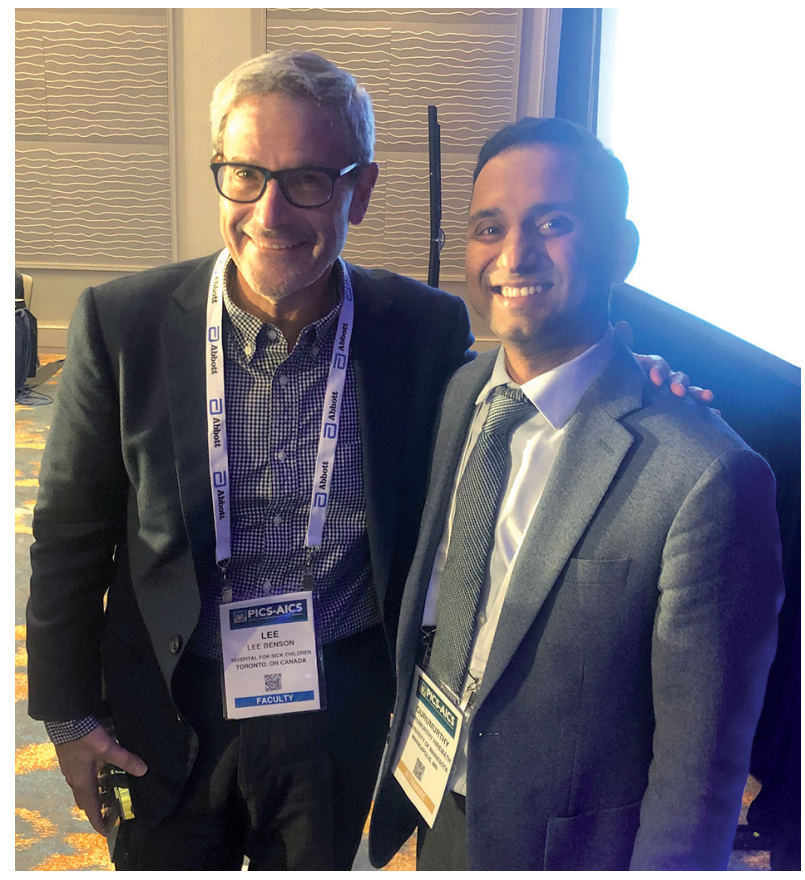

Figure 2. Dr. Lee Benson (SickKids Hospital, Toronto) with the Paediatric and congenital Interventional Cardiology Early-career Society (PICES) Vice President (Research) Gurumurthy Hiremath, MD (University of Minnesota Children's Hospital) after awarding of the second PICES Mentor Award at the Paediatric and Adult Interventional Cardiac Symposium (PICS-AICS) in San Diego 


\section{PICES@CSI-San Francisco}

The PICES group ended the year with a new opportunity to present cases as invited faculty at the CSI San Francisco conference. Selected by the PICES Executive Committee, five members successfully presented their experience with the following interventions: Case dilemma in < $15 \mathrm{~kg}$ atrial septal defect closure - Manish Bansal, MD (Baylor College of Medicine); Case dilemma in an older adult with atrial septal defect closure - Jason Anderson, MD (Mayo Clinic); Ductal stenting complication - Jess Randall, MD (Children's Hospital of Colorado); Right ventricular outflow tract stenting complication Konstantin Averin, MD (Stollery Children's Hospital); Duct closure at < $1000 \mathrm{~g}$ - Sarosh Batlivala, MD MSCl; and Arterial duct closure in a patient over 40 years of age Keeshan Britton, MD (Yale University School of Medicine).

\section{Future perspectives}

The year 2020 looks to be even more productive for the PICES group. Similarly to previous years, we plan to host sessions at the main interventional meetings including SCAI, PICS-AICS and CSI Frankfurt. In the autumn we are expecting interesting opportunities for PICES members during CSI America hosted for the first time in Denver, Colorado. We are also planning a PICES session during the Asia Pacific Interventional Cardiology Symposium (APICS) in Seoul, South Korea. Other events for 2020 include electing new Executive Committee members (President, Vice President [research]), pairing more mentors-mentees for the third mentorship program class, and hopefully a very active group listserv!

\section{Conflict of interest}

The authors declare no conflict of interest.

\section{References}

1. Gordon BM, Goldstein BH. Development of an early career society for pediatric and congenital interventional cardiologists: the PICES story. Catheter Cardiovasc Interv 2016; 88: 253-4.

2. Gordon BM. The PICES Group: highlights from breakout conferences 2015. Congenit Cardiol Today 2015; 13: 10-1.

3. Seckeler MD, Gordon BM, Williams DA, Goldstein BH. Use of smart technology for remote consultation in the pediatric cardiac catheterization laboratory. Congenit Heart Dis 2015; 10: E288-94.

4. Danon S, Gray RG, Crystal MA, et al. Expansion characteristics of stents used in congenital heart disease: serial dilation offers improved expansion potential compared to direct dilation: results from a Pediatric Interventional Cardiology Early Career Society (PICES) Investigation. Congenit Heart Dis 2016; 11: 741-50.

5. Gray RG, Menon SC, Johnson JT, et al. Acute and midterm results following perventricular device closure of muscular ventricular septal defects: a multicenter PICES investigation. Catheter Cardiovasc Interv 2017; 90: 281-9.

6. Aldoss O, Goldstein BH, Danon S, et al. Acute and mid-term outcomes of stent implantation for recurrent coarctation of the aorta between the Norwood operation and fontan completion: a multi-center Pediatric Interventional Cardiology Early Career Society Investigation. Catheter Cardiovasc Interv 2017; 90: 972-9.

7. Crystal MA, Morgan GJ, Danon S, et al. Serial versus direct dilation of small diameter stents results in a more predictable and complete intentional transcatheter stent fracture: a PICES Bench Testing Study. Pediatr Cardiol 2018; 39: 120-8.

8. Taggart NW, Gordon BM, Morgan GJ, Goldstein BH. Variation in anticoagulation practices in the congenital cardiac catheterization lab: results of a multinational PICES survey. Pediatr Cardiol 2019; 40: 53-60.

9. Zampi JD, Alghanem F, Yu S, et al. Relationship between time to left atrial decompression and outcomes in patients receiving venoarterial extracorporeal membrane oxygenation support: a multicenter Pediatric Interventional Cardiology Early-career society study. Pediatr Crit Care Med 2019; 20: 728-36.

10. Hiremath G, Morgan G, Kenny D, et al. Balloon expandable covered stents as primary therapy for hemodynamically stable traumatic aortic injuries in children. Catheter Cardiovasc Interv 2020; 95: 477-83. 